\title{
Validation of a method for simultaneous determina- tion of tocopherols and tocotrienols in cereals using Normal Phase HPLC
}

\author{
R. Gąsior ${ }^{1}$, M. Pieszka ${ }^{2}$ and F. Brzóska ${ }^{2}$ \\ National Research Institute of Animal Production, \\ ${ }^{1}$ Central Laboratory \\ 32-084 Morawica, Poland \\ ${ }^{2}$ Department of Animal Nutrition and Feed Science \\ 32-083 Balice, Poland
}

(Received 25 April 2008; revised version 23 December 2008; accepted 23 January 2009)

\begin{abstract}
A method for the simultaneous determination of tocols $(\alpha-, \beta-, \gamma-, \delta$-tocopherols and $\alpha-, \beta-, \gamma-$, $\delta$-tocotrienols) in cereals using Normal Phase-HPLC (Merck; column LiChroCART 250-4, Lichrospher Si 60, $5 \mu \mathrm{m}$ ) with fluorescent detection (Ex290 nm/Em350 nm) was validated. A mixture of hexane, ethyl acetate and acetic acid $(97.3: 1.8: 0.9, \mathrm{v} / \mathrm{v} / \mathrm{v})$ was used as the eluent $(1.6 \mathrm{ml} / \mathrm{min})$. The analyses were performed after spectrophotometric standardization of standard ethanol solutions. The residual coefficients of variation for the regression equation $y=\mathrm{ax}^{2}+\mathrm{bx}+\mathrm{c}$ were $0.001-3.8 \%$, with $\mathrm{r}^{2}>0.999$. The limit of quantitation was $0.05 \mathrm{mg} / \mathrm{kg}$, the upper limit of determination range from 40 to $60 \mathrm{mg} / \mathrm{kg}$, repeatability $6.2-11.8 \%$, and reproducibility $8.7-18.4 \%$. Uncertainty of the method $(\mathrm{P} \leq 0.05)$, estimated for the analyses performed in replicate, ranged from 28.9 to $85.9 \%$ for the tocol concentration of $0.05-0.80 \mu \mathrm{g} / \mathrm{ml}$ and from 14.7 to $27.3 \%$ for the concentrations above $0.80 \mu \mathrm{g} / \mathrm{ml}$. Recovery was $93.3-103.1 \%$. The analytical method described is precise, fast and inexpensive.
\end{abstract}

KEY WORDS: tocopherols, tocotrienols, cereals, validation, uncertainty, HPLC

\section{INTRODUCTION}

Tocopherols and tocotrienols, collectively known as tocols, are biologically active substances which are favourable for human and animal health. They belong to the group of fat-soluble vitamins, the best known of which is $\alpha$-tocopherol. Eight naturally occurring compounds with vitamin E activity have

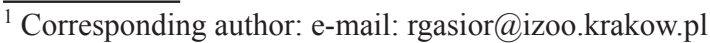


been identified: $\alpha$-, $\beta-, \gamma$ - and $\delta$-tocopherols and $\alpha$-, $\beta$-, $\gamma$ - and $\delta$-tocotrienols. The most important biological function of tocols is their antioxidative activity. Some studies have shown that $\alpha$-tocotrienol is a more potent free radical scavenger than $\alpha$-tocopherol, once considered the strongest antioxidant (Packer, 1995; Panfili et al., 2003). Tocopherols and tocotrienols protect against infertility and reproductive disorders as well as showing hypocholesterolaemic (Quereshi and Quereshi, 1993; Quereshi et al., 1995, 2002; Theriault et al., 1999; Ryynänen et al., 2004) and anticancer effects (Schwenke, 2002). Rich sources of tocols include vegetable oils, oilseeds and cereals, which are a staple of the human diet.

The main analytical technique used for determination of all tocols in a single run is Normal Phase High-Performance Liquid Chromatography (NP-HPLC) (KamalEldin et al., 2000; Panfili et al., 2003; Ryynänen et al., 2004) combined with smallscale sample preparation characterized by low consumption of organic solvents used for saponification and extraction, unlike the traditional sample preparation methods (AOAC, 1990). The good point of this technique, using mainly polar silica column and eluent based on hexane with polar organic substances addition, is to receive a very good separation of all the eight tocols. Reversed Phase High-Performance Liquid Chromatography (RP-HPLC) technique, with use of non-polar, e.g., octadecylsilica columns and on methanol based eluent, doesn't possess this merit. In this case, the separation of $\beta$ - and $\gamma$ - tocopherol isomers is impossible or very difficult. Although different procedures are used to prepare samples for analysis, extraction of saponified tocols from sample matrix appears to be the most universal (Panfili et al., 2003; Ryynänen et al., 2004).

The most reliable results possible are obtained by performing analyses after previous validation of the analytical method (Gasior et al., 2005; PN-EN ISO/IEC 17025:2005). Validation provides documented evidence that the procedure used is performing as designed. It characterizes the research method whose parameters are essential for showing that the method is reliable. Method characteristics includes parameters such as adjustment of the calibration curve to calibration points, limit of quantitation, range of determination, repeatability, reproducibility, limit of repeatability, uncertainty and recovery (Ellison et al., 2000; Dobecki, 2004). Especially, the general principles of uncertainty estimation were given by these authors. Despite an increasing number of validation and uncertainty studies (ISO, 1993; Arendarski, 2003), especially those dealing with physical measurements that are widely used in technical sciences, there are few studies concerning chemical analysis (Gassior et al., 2005).

The aim of the present study was to validate a method for simultaneous determination of the level of four isomers of tocopherols $(\alpha-, \beta-, \gamma-, \delta-)$ and four isomers of tocotrienols $(\alpha-, \beta-, \gamma-, \delta$-) in cereal grains by NP-HPLC technique, using an eluent composed of hexane, ethyl acetate and acetic acid (97.3:1.8:0.9, $\mathrm{v} / \mathrm{v} / \mathrm{v})$. The method was characterized for validation parameters mentioned above. 
An important aspect of the study, not found in the literature on chromatographic analyses, is a detailed discussion of the issues related to the identification and estimation of uncertainty components.

\section{MATERIAL AND METHODS}

\section{Reagents}

The reagents used were $n$-hexane with ethanol gradient grade for HPLC (Merck, Germany) and analytical grade ethyl acetate, acetic acid, isopropyl alcohol (2-propanol), ethanol 95-96\% (Chempur, Poland) potassium hydroxide and sodium chloride (POCH, Poland), and pyrogallol ( $>98 \%$, Fluka, USA). Sodium chloride $(10 \mathrm{~g} / \mathrm{l})$ and potassium hydrochloride $(600 \mathrm{~g} / \mathrm{l})$ solutions were made using double-distilled water. $\alpha$-tocopherol, $\alpha$-tocotrienol, $\beta$-tocopherol, $\gamma$-tocopherol, $\beta$-tocotrienol, $\gamma$-tocotrienol, $\delta$-tocopherol and $\delta$-tocotrienol standards were used. Tocotrienols were provided by Davos Life Science PTE LTD (Singapur), $\alpha$-tocopherol by Fluka (USA) and the other tocopherols by Calbiochem (USA). Inert gas (nitrogen) was also used to prepare the samples.

\section{Equipment}

Apparatus - an Agilent Series 1110 HPLC system (USA) equipped with a pump, autosampler and fluorescent detector was used. Data were integrated using Agilent ChemStation software. Conversions were performed on a PC using Excel. The following were also used to prepare the samples: screw-cap tubes (Schott, $12 \mathrm{ml}$ ), screw-cap vials $(15 \mathrm{ml})$, a vortex mixer (Vortex, Germany), an ultrasonic cleaner, a water bath and a feed grinder (Lab-mill-I, QC-114, Hungary). Standards were standardized using a Beckman DU640 spectrophotometer.

\section{Conditions for HPLC chromatographic analysis}

Chromatographic separation was carried out on a $25 \mathrm{~cm}$ long column LiChroCART 250-4, Lichrospher Si 60 (5 $\mu \mathrm{m}$, Merck, Germany) under the following conditions: FL detector, $\lambda$ wavelength: Ex $290 \mathrm{~nm}$ Em $330 \mathrm{~nm}$; injection 50 $\mu \mathrm{l}$; eluent (flow rate $1.6 \mathrm{ml} / \mathrm{min}$ ) - $n$-hexane:ethyl acetate:acetic acid (97.3:1.8:0.9, $\mathrm{v} / \mathrm{v} / \mathrm{v}$ ), duration of analysis $37 \mathrm{~min}$, pressure 58-68 bar. An ultrasonic cleaner was used prior to analysis for eluent degassing. Before each sample series was analysed, the column was conditioned for 70 min using $10 \%$ isopropanol solution in $n$-hexane $(\mathrm{v} / \mathrm{v})$. 


\section{Standardization of standard solutions}

Standards were standardized using spectrophotometric measurements at the following wavelengths: $292 \mathrm{~nm}$ ( $\alpha$-tocopherol, $\alpha$-tocotrienol), $296 \mathrm{~nm}$ ( $\beta$-tocopherol, $\beta$-tocotrienol), $297 \mathrm{~nm}(\gamma$-tocotrienol, $\delta$-tocotrienol) and $298 \mathrm{~nm}(\gamma$ tocopherol, $\delta$-tocopherol). The concentrations of standard tocol solutions, made in ethanol matrix, were corrected based on tabular data for extinction coefficient $\left(\mathrm{E}_{1 \mathrm{~cm}}{ }^{1 \%}\right)$ of $75.8,89.4,91.4,87.3,86.0,86.2,91.0$ and 85.8 for $\alpha$-tocopherol $\beta$-tocopherol, $\gamma$-tocopherol, $\delta$-tocopherol, $\alpha$-tocotrienol, $\beta$-tocotrienol, $\gamma$-tocotrienol and $\delta$-tocotrienol, respectively (Eitenmiller and Landen, 1999). Standard solutions were kept under nitrogen at $2-8^{\circ} \mathrm{C}$ in vials wrapped in aluminium foil. This way stored standards solutions were rather stable through about 16 months, although the extinctions of the tocopherols and $\beta$-tocotrienol solutions seemed slightly to increase no more than about $10 \%$. The standards solutions were initially standardized once every few days, but then more occasionally. The last standardization was performed after about 500 days.

\section{Preparation of standard solutions for analysis}

For recovery tests, concentrated solutions of tocols, nominally $2000 \mu \mathrm{g} / \mathrm{ml}$ of each in ethanol, were used to make a standard mixture of tocols $\left(\mathrm{S}_{\text {add }}\right)$. Nominal concentrations of each tocol in $\mathrm{S}_{\text {add }}$ were $100 \mu \mathrm{g} / \mathrm{ml}$. For routine analyses, standard mixtures of tocols $\left(\mathrm{S}_{\text {rout }}\right)$ were also made by diluting concentrated alcohol solutions of each tocol with $1 \%$ isopropanol solution in $n$-hexane $(\mathrm{v} / \mathrm{v})$, until the nominal concentrations of $0-24 \mu \mathrm{g} / \mathrm{ml}$ were obtained. Nominal tocol concentrations in the standards were adjusted to obtain actual concentrations, based on the results of previous standardization. The analyses of $\mathrm{S}_{\text {rout }}$ mixtures were used to plot the calibration curve, which served as a basis for determining the concentration of tocols in the analysed samples.

\section{Preparation of samples and making analyses}

Ground samples (approx. $100 \mathrm{~g}$ ) were mixed, and $0.5 \mathrm{~g}$ of the representative sample of a given material was weighed to a reading accuracy of $0.0001 \mathrm{~g}$ and put into $12 \mathrm{ml}$ vials (Schott). One $\mathrm{ml}$ of pyrogallol in ethanol $(60 \mathrm{~g} / \mathrm{l}), 0.5 \mathrm{ml}$ of the aqueous solution of potassium hydroxide $(600 \mathrm{~g} / 1), 0.5 \mathrm{ml}$ of the aqueous solution of sodium chloride $(10 \mathrm{~g} / \mathrm{l})$ and $0.5 \mathrm{ml}$ of ethanol were added. Vials were sealed, shaken on a vortex mixer for approx. $10 \mathrm{sec}$, and transferred to a $70^{\circ} \mathrm{C}$ water bath, where the samples were saponified for $45 \mathrm{~min}$. After cooling, $4 \mathrm{ml}$ of aqueous sodium chloride solution $(10 \mathrm{~g} / \mathrm{l})$ was added, followed by double extraction of $4 \mathrm{ml}$ ethyl acetate and $n$-hexane mixture $(1: 9 ; \mathrm{v} / \mathrm{v})$ and 
shaking (Vortex) of the sealed vial for approx. $0.1 \mathrm{~min}$. The extracts were combined and evaporated (15 ml vials) to dryness under nitrogen in a water bath $\left(40^{\circ} \mathrm{C}\right)$. The remainder was diluted in $0.5 \mathrm{ml}$ of $1 \%$ isopropanol and $n$-hexane mixture $(\mathrm{v} / \mathrm{v})$, and the solutions obtained were injected $(50 \mu \mathrm{l})$ on a chromatographic column. The same procedure was used for making blank samples except that no sample was added. When samples with the standard were prepared (recovery tests), $0.1 \mathrm{ml}$ of the $\mathrm{S}_{\text {add }}$ standard was added to the vial containing a weighed sample prior to saponification.

Chromatographic analyses were performed for $\mathrm{S}_{\text {rout }}$ standards, blank samples and cereal samples. The concentration $(\mathrm{mg} / \mathrm{kg})$ of $\alpha$-tocopherol, $\alpha$-tocotrienol, $\beta$-tocopherol, $\gamma$-tocopherol, $\beta$-tocotrienol, $\gamma$-tocotrienol, $\delta$-tocopherol and $\delta$-tocotrienol in the analysed material (in order of appearance on the chromatogram) was determined in relation to the $\mathrm{S}_{\text {rout }}$ standard, with regard to blank sample and recovery. Recovery was determined by making chromatographic analyses of $\mathrm{S}_{\text {rout }}$ standards, cereal samples and cereal samples with the added $\mathrm{S}_{\text {add }}$ standard.

\section{Calibration curves, limit of quantitation, and ranges of determination}

In the nominal range ( 0 to approx. $24 \mu \mathrm{g} / \mathrm{ml}$ ) of each tocol, 14 standard mixture solutions (14-point calibration), 10 standard mixture solutions (10-point calibration) and 4 standard mixture solutions (4-point calibration) were made. Successive solutions were obtained after appropriate dilution of concentrated alcohol solutions of each tocol (nominally $2000 \mu \mathrm{g} / \mathrm{ml}$ in ethanol) with $1 \%$ isopropanol solution in $n$-hexane (v/v). Nominal concentrations of tocols were adjusted to obtain actual concentrations, based on the results of previous standardization. Following the chromatographic analysis of the above solutions, two types of calibration curves were plotted for each component: linear $\mathrm{y}=\mathrm{ax}+\mathrm{b}$ and second: degree polynomial $\mathrm{y}=\mathrm{ax}^{2}$ $+\mathrm{bx}+\mathrm{c}$, for which the coefficient of correlation $\mathrm{r}^{2}$ and residual coefficient of variation were calculated (Excel). The residual coefficient of variation was defined as a relative mean deviation (\%) from the regression line (residual error) in relation to the mean independent variable for calibration curve (x axis). For routine determination of tocol concentrations in the samples, a 4-point polynomial calibration curve was plotted (in the range from 0 to approx. $24 \mu \mathrm{g} / \mathrm{ml}$ for each tocol). Partial uncertainty, which is a component of method uncertainty, was determined for this curve.

The limits of quantitation (LOQ) for individual tocol isomers were determined as the lowest, non-zero concentration of a given tocol, selected from the range of calibration curve, and expressed in $\mu \mathrm{g} / \mathrm{ml}$ and in $\mathrm{mg} / \mathrm{kg}$.

The range of tocol determinations was determined based on the concentration of tocols from the calibration range, with regard to the relationship between method uncertainty and the level of concentration of the tocol being determined. For each tocol determined, two ranges of determination were assigned: the first range - from 
the limit of quantitation to a certain concentration from the calibration curve, for which method uncertainty stabilizes, reaching as low a value as possible; the second range - from the upper limit of the first range to adequately converted amounts of tocols resulting from the upper ranges of calibration curves. These amounts, treated as maximal and capable of being used for practical determination of tocol concentrations in the analysed samples, were determined based on the analytical procedure used (with regard to recovery), assuming a double dilution of the sample solution before chromatographic analysis, and increased by approx. 15\% (this excessive calibration range had no significant effect on the analysis results). The range of determinations was expressed in $\mathrm{mg} / \mathrm{kg}$.

\section{Repeatability, reproducibility, limit of repeatability}

Repeatability was defined as being not lower than the pooled coefficient of variation $\left(\mathrm{CV}_{k}\right)$ for determinations of tocols, carried out in a given series and on a given day, in cereal grain samples in replicate, and calculated from the formula (1):

$$
C V_{k}=\sqrt{\frac{\sum_{k} C V^{2}}{k}}
$$

where: the coefficient of variation $(\mathrm{CV})$ for determinations of a given tocol in a given sample was calculated from the formula (2):

$$
C V=100 \times \frac{S D}{X_{a v}}
$$

where: $k$ - number of samples; $S D$ - standard deviation for analysis of two samples of the material studied; $X_{a v}$ - mean from two measurements of a given sample.

Reproducibility was defined as being not lower than the pooled coefficient of variation for determinations of tocols in cereal grain samples, carried out in replicate on the same day and analogous determinations of the same samples on the second day. To determine reproducibility, consecutive pairs of determinations from both days were combined, using analogous formulas as for the repeatability calculation.

Double the repeatability value was assumed as the limit of repeatability.

\section{Uncertainty}

The uncertainty of the method (confidence level 95\%) was calculated by expansion (coverage factor $k_{e}=2$ ) of combined standard uncertainty (confidence level 68\%). Combined standard uncertainty was calculated from partial standard uncertainties, in accordance with the law of uncertainty propagation (ISO, 1993; Ellison et al., 2000). According to this principle, combined standard uncertainty 
$u_{c}(y(p, q .)$.$) for the function that is the sum or difference of components \mathrm{p}, \mathrm{q} .$. (in model equation (5) $p=C_{p}, q=C_{b l}$ ) was calculated from the equation (3):

$$
u_{c}(y(p, q . .))=\sqrt{u(p)^{2}+u(q)^{2}+\ldots}
$$

For the function that is the product or quotient of factors $p, q, .$. (e.g., in model equation (5) $\left.p=V, q=f_{d}\right)$, combined relative (\%) standard uncertainty $\frac{u_{c}(y(p, q .))}{y}$ was calculated from the equation (4):

$$
\frac{u_{c}(y(p, q . .))}{y}=\sqrt{\left(\frac{u(p)}{p}\right)^{2}+\left(\frac{u(q)}{q}\right)^{2}+\ldots}
$$

where the terms under the radical in equation (3) are the squares of partial standard uncertainties, and in equation (4) they are the squares of partial relative standard uncertainties.

Partial uncertainties were identified based on the function expressed by the model equation (5):

$$
P=100 \times \frac{\left(C_{p}-C_{b l}\right) \times V \times f_{d}}{n_{g} \times R} \quad(\mathrm{mg} / \mathrm{kg})
$$

where: $P$ - tocol content of the sample $(\mathrm{mg} / \mathrm{kg}) ; C_{p}$ - tocol concentration in the sample of the material analysed $(\mu \mathrm{g} / \mathrm{ml})$, determined from the calibration curve; $C_{b l}$ - tocol concentration in the blank sample $(\mu \mathrm{g} / \mathrm{ml})$, determined from the calibration curve; $V$ - volume $(\mathrm{ml})$ of the isopropanol added in $n$-hexane $(1 \%$ isopropanol, $\mathrm{v} / \mathrm{v})$ to the samples after evaporation of the extract; $f_{d}$ factor of possible dilutions performed during sample preparation and analysis; $\mathrm{n}_{\mathrm{g}}$ - weighed amount of the sample $(\mathrm{g}) ; R$ - recovery.

Partial standard uncertainty of the apparatus calibration $u\left(c_{\theta}\right)$ (uncertainty of measured concentration $\left.\mathrm{c}_{0}\right)$ was calculated using the formulas $(6,7,8)$ :

$$
\begin{gathered}
u\left(c_{0}\right)=S_{x^{\wedge}} \sqrt{\frac{1}{p}+\frac{1}{n_{k}}+\frac{\left(c_{0}-c_{a v}\right)^{2}}{S_{x x}}} \\
S_{x^{\wedge}}=\sqrt{\frac{\sum_{i=1}^{n}\left(c_{i}-c^{\wedge}\right)^{2}}{n-2}} \\
S_{x x}=\sum_{i=1}^{n}\left(c_{i}-c_{a v}\right)^{2}
\end{gathered}
$$

where: $S_{x^{\wedge}}$ - the mean square deviation of concentration $c_{i}$ in the standard solution from concentration $c^{\wedge}$ read from the calibration curve. $S_{x x}$ - the sum of squares for the deviation of concentrations $c_{i}$ from the mean concentration $c_{a v}$ of a given tocol; 
$\mathrm{p}$ - the number of measurements of the same solution of a given sample, read as $c_{0}$; $n_{k}$ - the number of calibration points (concentration levels of a given tocol).

Issues related to the identification of uncertainty factors and the calculation of combined uncertainty are treated at length in the Discussion.

\section{Recovery}

The recovery of all tocols was tested on different cereal samples $(n=8)$. Recovery was determined by comparing the concentration of a given component added to the sample, measured in relation to the calibration curve plotted based on $\mathrm{S}_{\text {rout }}$ standards, with the expected concentration.

\section{Materials studied}

In validation tests, repeatability was determined using barley, wheat, triticale, rye and oat grain (a total of 30 samples, $k=30$, formula 1), and reproducibility (determinations on two different dates) was determined using 10 samples of barley grain and 2 samples of oat grain $(k=12 \times 2=24$, formula 1$)$. In addition, routine analyses of 10 samples of 3 varieties of barley grain (first and second variety from 3 regions, third variety from 4 regions), 3 samples of wheat grain (one variety, 3 regions), 2 samples of triticale grain (one variety, 2 regions) and 2 samples of oat grain (a total of 17 samples) were performed in replicate. After grinding, cereal grains were prepared according to analytical procedures and analysed.

\section{RESULTS}

The calibration curves, made in a wide range of concentrations from approx. $0.05 \mu \mathrm{g} / \mathrm{ml}$ ( $2.5 \mathrm{ng} /$ injection) to approx. $24 \mu \mathrm{g} / \mathrm{ml}$ (1200 ng/injection) were characterized by coefficients of correlation $\mathrm{r}^{2}$ exceeding 0.999 and residual coefficients of variation of $0.1-5.3 \%$ (linear calibration) and $0.001-3.8 \%$ (polynomial calibration).

The limit of quantitation was determined from the calibration curve as the lowest, non-zero concentration of tocols in the standard solution, and amounted to 0.05 $\mu \mathrm{g} / \mathrm{ml}(0.05 \mathrm{mg} / \mathrm{kg})$.

Two ranges of determination were set, as determined by changing uncertainty value according to the concentration of the tocols being determined. These ranges (with greater uncertainty) varied from 0.05 to $0.80 \mathrm{mg} / \mathrm{kg}$ and (with smaller uncertainty) from 0.81 to: $60 \mathrm{mg} / \mathrm{kg}$ ( $\alpha$-tocopherol), $45 \mathrm{mg} / \mathrm{kg}$ ( $\alpha$-tocotrienol), $60 \mathrm{mg} / \mathrm{kg}$ ( $\beta$-tocopherol), $60 \mathrm{mg} / \mathrm{kg}$ ( $\gamma$-tocopherol), $60 \mathrm{mg} / \mathrm{kg}$ ( $\beta$-tocotrienol), $50 \mathrm{mg} / \mathrm{kg}(\gamma$-tocotrienol), $50 \mathrm{mg} / \mathrm{kg}$ ( $\delta$-tocopherol) and $40 \mathrm{mg} / \mathrm{kg}$ ( $\delta$-tocotrienol). 
Repeatability and reproducibility $\left(C V_{k}, \%\right)$ were 7.1 and 12.0 for $\alpha$-tocopherol, 6.7 and 12.0 for $\alpha$-tocotrienol, 10.6 and 18.4 for $\beta$-tocopherol, 8.6 and 8.7 for $\gamma$-tocopherol, 6.2 and 11.8 for $\beta$-tocotrienol, 11.5 and 12.1 for $\gamma$-tocotrienol, 11.8 and 14.0 for $\delta$-tocopherol, and 8.7 and 11.0 for $\delta$-tocotrienol, respectively. The limits of repeatability (threshold $C V_{k}, \%$ ) for these tocols were 14.1, 13.5, 21.2, 17.2, $12.4,23.0,23.6$ and 17.3, respectively.

The sources of uncertainty were identified based on the model equation (5). The diagram (Figure 1) was used to create uncertainty budgets for each tocol. A sample budget for the determination of $\alpha$-tocopherol content made in replicate is shown in Table 1 (threshold level of concentration $=0.80 \mu \mathrm{g} / \mathrm{ml}$ ) and in Table 2 (threshold level of concentration $=0.05 \mu \mathrm{g} / \mathrm{ml}$ ). The uncertainties of the method

\begin{tabular}{|c|c|}
\hline $\begin{array}{l}\quad 1 \\
\quad \text { Repeatability / reproducibility } \\
\text { Uncertainty factors included in } \\
\text { repeatability/reproducibility, associated } \\
\text { with } \mathrm{C}, \mathrm{V}, \mathrm{r}, \mathrm{n}_{\mathrm{g}} \text {, and designated as (1) }\end{array}$ & 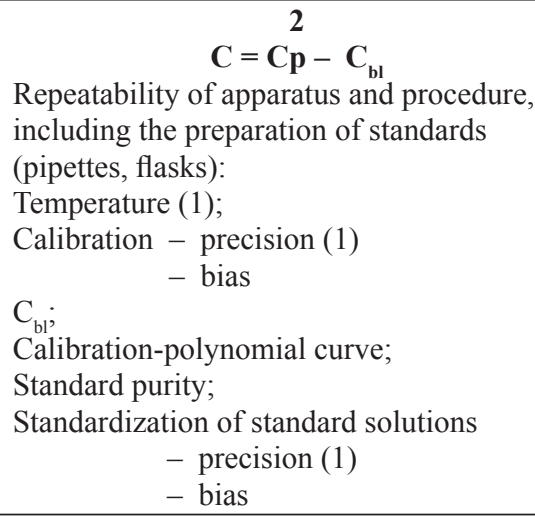 \\
\hline $\begin{array}{l}\qquad \mathbf{3} \\
\mathbf{V} \\
\text { Flasks and pipettes for preparation of } \\
\text { sample and standards: } \\
\text { Temperature (1); } \\
\text { Calibration - precision (1) } \\
\quad-\text { bias }\end{array}$ & $\begin{array}{l}\text { Dilutions-f } \\
\text { Pipettes used for dilutions: } \\
\text { Temperature (1); } \\
\begin{array}{c}\text { Calibration }- \text { precision (1) } \\
- \text { bias }\end{array}\end{array}$ \\
\hline 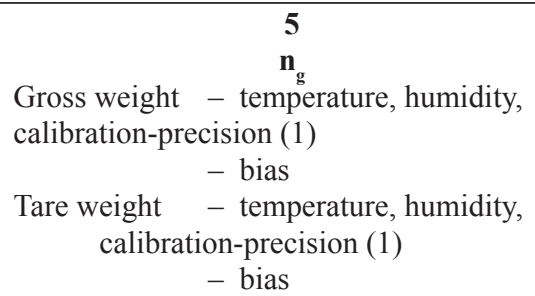 & $\begin{array}{c}\mathbf{6} \\
\mathbf{R} \\
\text { Losses incurred during the procedure }\end{array}$ \\
\hline
\end{tabular}

Figure 1. Diagram of uncertainty sources. Figure in brackets (1) next to a source of uncertainty denotes that a given element was already included in the repeatability-reproducibility factor in the uncertainty budget. The source of uncertainty, designated with a bracketed figure, is not treated as a separate factor affecting method uncertainty and as such it is not distinguished in the uncertainty budget 
Table 1 . Uncertainty budget, $\alpha$-tocopherol, analyses performed in replicate, threshold concentration level $=0.80 \mu \mathrm{g} / \mathrm{ml}$

\begin{tabular}{|c|c|c|c|}
\hline \multirow[t]{2}{*}{ Factor of uncertainty } & \multirow[t]{2}{*}{ Description } & \multicolumn{2}{|c|}{$\begin{array}{c}\text { Relative } \\
\text { partial standard } \\
\text { uncertainties }\end{array}$} \\
\hline & & $\mathrm{u}_{\mathrm{i}} \%$ & $\mathrm{u}_{\mathrm{i}} \% \mathrm{o}^{2}$ \\
\hline $\begin{array}{l}\text { Repeatability-reproducibility, blank } \\
\text { sample, apparatus calibration }\end{array}$ & $\mathrm{u}_{2 \text { rep0cal }} \%$ & 8.60 & 92.16 \\
\hline Standard purity & $u_{i} \%=a_{i} / \sqrt{ } 3$ & 1.73 & 3.00 \\
\hline Standardization & $u_{i} \%=a_{i} / \sqrt{ } 3$ & 1.154 & 1.33 \\
\hline Recovery & Mean standard deviation $=\mathrm{u}_{\mathrm{i}} \%$ & 2.20 & 4.84 \\
\hline $\begin{array}{l}\text { Sample preparation } \\
\text {-pipette } \\
\text { Standard preparation }\end{array}$ & $u_{i} \%=a_{i} / \sqrt{ } 3$ & 1.154 & 1.33 \\
\hline $\begin{array}{l}-1 \text { pipette } \\
-2 \text { flasks }\end{array}$ & $\begin{array}{ll}\mathrm{a}_{\mathrm{i}}=2 \% ; & \mathrm{u}_{\mathrm{i}} \%=\mathrm{a}_{\mathrm{i}} / \sqrt{ } 3 \\
\mathrm{a}_{\mathrm{i}}=0,6 \% ; & \mathrm{u}_{\mathrm{i}} \%=\mathrm{a}_{\mathrm{i}} / \sqrt{3} \\
\mathrm{a}_{\mathrm{i}}=0,6 \% ; & \mathrm{u}_{\mathrm{i}} \%=\mathrm{a}_{\mathrm{i}} / \sqrt{3}\end{array}$ & $\begin{array}{l}1.154 \\
0.346 \\
0.346\end{array}$ & $\begin{array}{l}1.33 \\
0.12 \\
0.12\end{array}$ \\
\hline $\begin{array}{l}\text { Dilutions } \\
-2 \text { pipettes }\end{array}$ & $\begin{array}{ll}\mathrm{a}_{\mathrm{i}}=2 \% ; & \mathrm{u}_{\mathrm{i}} \%=\mathrm{a}_{\mathrm{i}} / \sqrt{ } 3 \\
\mathrm{a}_{\mathrm{i}}=2 \% ; & \mathrm{u}_{\mathrm{i}} \%=\mathrm{a}_{1} / \sqrt{ } 3\end{array}$ & $\begin{array}{l}1.154 \\
1.154\end{array}$ & $\begin{array}{l}1.33 \\
1.33\end{array}$ \\
\hline Combined relative standard uncertainty, $\mathrm{u} \%{ }_{68}$ & $\sqrt{\sum} u_{i} \%{ }^{2}=u^{1} \%_{68}$ & 9.42 & \\
\hline
\end{tabular}

Relative method uncertainty $\mathrm{U} \%{ }_{95}$ after expansion, $\mathrm{k}_{\mathrm{e}}=2$

$$
\mathrm{U} \%_{95}=2 \times \mathrm{u}_{68}^{\mathrm{e}}=18.8
$$

$\mathrm{a}_{\mathrm{i}}$ - limit of error for measuring equipment or standard, estimated based on the authors' own observations or on data provided by manufacturers, concerning the i-th uncertainty factor

Table 2. Uncertainty factor, $\alpha$-tocopherol; analyses performed in replicate, threshold concentration level $=0.05 \mu \mathrm{g} / \mathrm{ml}$

\begin{tabular}{|c|c|c|c|c|}
\hline \multirow[t]{2}{*}{ Uncertainty factor } & \multirow[t]{2}{*}{ Description } & & \multicolumn{2}{|c|}{$\begin{array}{l}\text { Relative partial } \\
\text { standard } \\
\text { uncertainties }\end{array}$} \\
\hline & & & $\mathrm{u}_{\mathrm{i}} \%$ & $u_{i} \%{ }^{2}$ \\
\hline $\begin{array}{l}\text { Repeatability-reproducibility, blank } \\
\text { sample, apparatus calibration }\end{array}$ & $\mathrm{u}_{2 \text { rep } 0 \mathrm{cal}} \%$ & & 28.86 & 832.91 \\
\hline Standard purity & $a_{i}=3 \% ; \quad u_{i} \%=a_{i} / \sqrt{ } 3$ & & 1.73 & 3.00 \\
\hline Standardization & $\mathrm{a}_{\mathrm{i}}=2 \% ; \quad \mathrm{u}_{\mathrm{i}} \%=\mathrm{a}_{\mathrm{i}} / \sqrt{ } 3$ & & 1.154 & 1.33 \\
\hline Recovery & $\begin{array}{l}\text { Mean standard } \\
\text { deviation }=\mathrm{u}_{\mathrm{i}} \%\end{array}$ & & 2.20 & 4.84 \\
\hline $\begin{array}{l}\text { Sample preparation } \\
\text { pipette }\end{array}$ & $\mathrm{a}_{\mathrm{i}}=2 \% ; \quad \mathrm{u}_{\mathrm{i}} \%=\mathrm{a}_{\mathrm{i}} / \sqrt{ } 3$ & & 1.154 & 1.33 \\
\hline $\begin{array}{l}\text { Standard preparation: } \\
1 \text { pipette } \\
2 \text { flasks }\end{array}$ & $\begin{array}{l}a_{i}=2 \% ; \quad u_{i} \%=a_{i} / \sqrt{ } 3 \\
a_{i}=0,6 \% ; u_{i} \%=a_{i} / \sqrt{ } 3 \\
a_{i}=0,6 \% ; u_{i} \%=a_{i} / \sqrt{ } 3\end{array}$ & & $\begin{array}{l}1.154 \\
0.346 \\
0.346\end{array}$ & $\begin{array}{l}1.33 \\
0.12 \\
0.12\end{array}$ \\
\hline $\begin{array}{l}\text { Dilutions } \\
2 \text { pipettes }\end{array}$ & $\begin{aligned} \mathrm{a}_{\mathrm{i}}=2 \% ; & \mathrm{u}_{\mathrm{i}} \%=\mathrm{a}_{\mathrm{i}} / \sqrt{ } 3 \\
\mathrm{a}_{\mathrm{i}}=2 \% ; & \mathrm{u}_{\mathrm{i}} \%=\mathrm{a}_{\mathrm{i}} / \sqrt{ } 3\end{aligned}$ & & $\begin{array}{l}1.154 \\
1.154\end{array}$ & $\begin{array}{l}1.33 \\
1.33\end{array}$ \\
\hline Combined relative standard uncertainty, $\mathrm{u}_{6}{ }_{68}$ & $\sqrt{ } \sum \mathrm{u}_{\mathrm{i}} \% \mathrm{o}^{2}=\mathrm{u} \%_{68}$ & & 29.11 & \\
\hline Relative method uncertainty $\mathrm{U}{ }_{95}$ after expa & $\begin{array}{l}\text { ansion, } \mathrm{k}_{\mathrm{e}}=2 \\
\qquad \mathrm{U} \%_{05}=2 \times \mathrm{u}_{68}=\end{array}$ & 58.2 & & \\
\hline
\end{tabular}

$\mathrm{a}_{\mathrm{i}}$ - as in Table 1 
Table 3. (Relative) method uncertainties $\mathrm{U} \%_{95}, \mathrm{k}_{\mathrm{e}}=2$; analyses performed in replicate

\begin{tabular}{lcc}
\hline \multirow{2}{*}{ Tocol } & \multicolumn{2}{c}{ Relative method uncertainty, $\mathrm{U}_{05}(\%)$ for the range } \\
\cline { 2 - 3 } & $0.05-0.80, \mu \mathrm{g} / \mathrm{ml} \approx \mathrm{mg} / \mathrm{kg}$ & over $0.80, \mu \mathrm{g} / \mathrm{ml} \approx \mathrm{mg} / \mathrm{kg}$ \\
\hline$\alpha$-tocopherol & 58.2 & 18.8 \\
$\alpha$-tocotrienol & 82.0 & 20.3 \\
$\beta$-tocopherol & 55.5 & 27.3 \\
$\gamma$-tocopherol & 41.3 & 14.7 \\
$\beta$-tocotrienol & 36.9 & 19.6 \\
$\gamma$-tocotrienol & 37.3 & 19.1 \\
$\delta$-tocopherol & 85.9 & 21.6 \\
$\delta$-tocotrienol & 28.9 & 17.3 \\
\hline
\end{tabular}

Table 4. Effect of the concentration of tocols on relative standard uncertainty $u_{2 \text { repocal }} \%$ of the repeatability-reproducibility, blank sample and apparatus calibration factors; analyses performed in replicate

\begin{tabular}{|c|c|c|c|c|}
\hline \multirow[t]{2}{*}{ Tocol } & \multicolumn{3}{|c|}{$\begin{array}{l}\text { Relative standard uncertainty of the repeatability-re- } \\
\text { producibility, blank sample and apparatus calibration } \\
\text { factors, } \mathrm{u}_{2 \text { ren } 0 \text { cal }} \%\end{array}$} & \multirow{2}{*}{$\begin{array}{l}\text { Relative standard uncer- } \\
\text { tainty: repeatability-repro- } \\
\text { ducibility only }\left(\mathrm{CV}_{\mathrm{k} 2}\right)\end{array}$} \\
\hline & $\begin{array}{c}0.05 \\
\mu \mathrm{g} / \mathrm{ml} \approx \mathrm{mg} / \mathrm{kg}\end{array}$ & $\begin{array}{c}0.80 \\
\mu \mathrm{g} / \mathrm{ml} \approx \mathrm{mg} / \mathrm{kg}\end{array}$ & $\begin{array}{c}10 \\
\mu \mathrm{g} / \mathrm{ml} \approx \mathrm{mg} / \mathrm{kg}\end{array}$ & \\
\hline$\alpha$-tocopherol & 28.9 & 8.6 & 8.5 & 8.4 \\
\hline$\alpha$-tocotrienol & 40.7 & 8.8 & 8.5 & 8.5 \\
\hline$\beta$-tocopherol & 27.5 & 13.1 & 13.0 & 13.0 \\
\hline$\gamma$-tocopherol & 20.3 & 6.2 & 6.1 & 6.1 \\
\hline$\beta$-tocotrienol & 17.8 & 8.4 & 8.3 & 8.3 \\
\hline$\gamma$-tocotrienol & 18.2 & 8.6 & 8.6 & 8.6 \\
\hline$\delta$-tocopherol & 42.8 & 10.2 & 9.9 & 9.9 \\
\hline$\delta$-tocotrienol & 14.0 & 7.8 & 7.8 & 7.8 \\
\hline
\end{tabular}

Table 5. Recoveries (\%) of tocopherols and tocotrienols $(\mathrm{n}=8)$

\begin{tabular}{lcc}
\hline Tocol & Mean recoveries & Coefficient of variation $(\mathrm{CV})$ \\
\hline$\alpha$-tocopherol & 101.0 & 6.1 \\
$\alpha$-tocotrienol & 93.3 & 4.0 \\
$\beta$-tocopherol & 101.6 & 2.3 \\
$\gamma$-tocopherol & 97.1 & 2.3 \\
$\beta$-tocotrienol & 103.1 & 3.9 \\
$\gamma$-tocotrienol & 96.9 & 2.7 \\
$\delta$-tocopherol & 93.6 & 1.7 \\
$\delta$-tocotrienol & 99.1 & 1.9 \\
\hline
\end{tabular}

$\mathrm{U} \%{ }_{95}\left(\mathrm{k}_{\mathrm{e}}=2\right)$ for two ranges of concentration of the tocols determined, estimated for the analyses made in replicate, are given in Table 3 . The ranges given in the Table 3, expressed in $\mu \mathrm{g} / \mathrm{ml}$ and $\mathrm{mg} / \mathrm{kg}$, are practically equivalent, which is due to the appropriate conversion of the results according to the methodology 


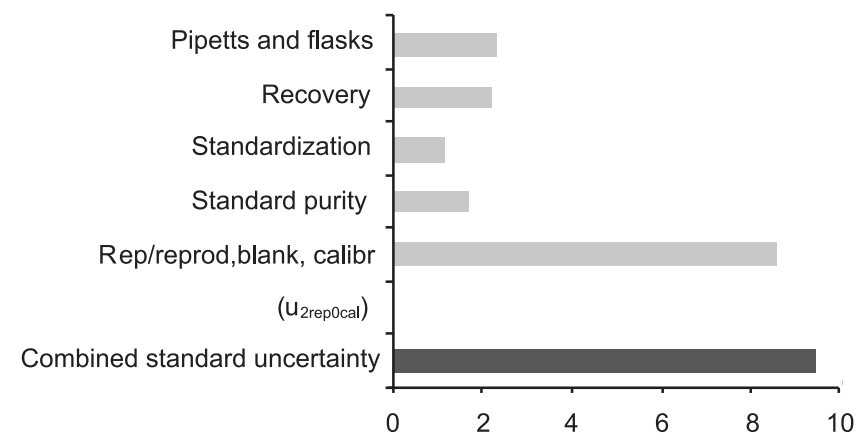

Figure 2. Proportions of components of relative (\%) method standard uncertainties for $\alpha$-tocopherol concentrations above $0.80(\mu \mathrm{g} / \mathrm{ml} \approx \mathrm{mg} / \mathrm{kg})$; analyses performed in replicate

used. The effect of the tocol concentration on relative standard uncertainty $\left(\mathrm{u}_{2 \mathrm{re}-}\right.$ pocal $\%$ ) of the repeatability-reproducibility factor, blank sample and apparatus calibration, is shown in Table 4, and the proportions of individual components of relative standard uncertainties (using the example of $\alpha$-tocopherol, c $>0.80 \mu \mathrm{g} / \mathrm{ml}$ ) are shown in Figure 2.

The recovery (\%) of tocols from the cereal grains analysed are given in Table 5. The results of routine analyses of cereal grain samples are given in Table 6. A sample chromatogram for the analysis of barley sample is shown in Figure 3.

Table 6. Tocol content of different cereal varieties

\begin{tabular}{|c|c|c|c|c|c|c|}
\hline \multirow{3}{*}{ Tocol } & \multicolumn{3}{|c|}{ Barley } & \multirow[b]{2}{*}{$\begin{array}{l}\text { Wheat } \\
k^{\prime}=3\end{array}$} & \multirow[b]{2}{*}{$\begin{array}{c}\text { Triticale } \\
\mathrm{k}^{\prime}=2\end{array}$} & \multirow[b]{2}{*}{$\begin{array}{l}\text { Oat } \\
\mathrm{k}^{\prime}=2\end{array}$} \\
\hline & $\begin{array}{c}\mathrm{A} \\
\mathrm{k}^{\prime}=3\end{array}$ & $\begin{array}{c}\mathrm{B} \\
\mathrm{k}^{\prime}=3\end{array}$ & $\begin{array}{c}\mathrm{C} \\
\mathrm{k}^{\prime}=4\end{array}$ & & & \\
\hline & \multicolumn{6}{|c|}{ Tocols, $\mathrm{mg} / \mathrm{kg} \pm \mathrm{SD}$} \\
\hline$\alpha$-tocopherol & $10.15 \pm 1.03$ & $8.85 \pm 1.01$ & $8.56 \pm 1.71$ & $17.07 \pm 4.93$ & $17.76 \pm 2.49$ & $13.12 \pm 0.83$ \\
\hline$\alpha$-tocotrienol & $28.41 \pm 1.03$ & $29.30 \pm 3.45$ & $47.44 \pm 1.02$ & $6.99 \pm 1.96$ & $19.66 \pm 3.96$ & $26.19 \pm 1.88$ \\
\hline$\beta$-tocopherol & $0.53 \pm 0.04$ & $0.26 \pm 0.14$ & $0.26 \pm 0.09$ & $7.93 \pm 2.42$ & $4.14 \pm 0.66$ & $0.89 \pm 0.10$ \\
\hline$\gamma$-tocopherol & $4.68 \pm 0.56$ & $1.74 \pm 0.71$ & $1.65 \pm 0.51$ & $0.09 \pm 0.04$ & $0.17 \pm 0.02$ & $0.21 \pm 0.18$ \\
\hline$\beta$-tocotrienol & $5.66 \pm 1.24$ & $3.68 \pm 1.12$ & $4.25 \pm 0.39$ & $31.75 \pm 6.38$ & $31.32 \pm 5.95$ & $3.82 \pm 0.33$ \\
\hline$\gamma$-tocotrienol & $11.62 \pm 0.56$ & $7.69 \pm 1.67$ & $12.74 \pm 2.37$ & $0.66 \pm 0.63$ & $0.17 \pm 0.12$ & $0.11 \pm 0.06$ \\
\hline$\delta$-tocopherol & $0.98 \pm 0.23$ & nd & nd & nd & nd & nd \\
\hline$\delta$-tocotrienol & $1.30 \pm 0.05$ & $1.13 \pm 0.30$ & $1.14 \pm 0.06$ & $0.24 \pm 0.08$ & $0.15 \pm 0.07$ & $0.13 \pm 0.07$ \\
\hline
\end{tabular}




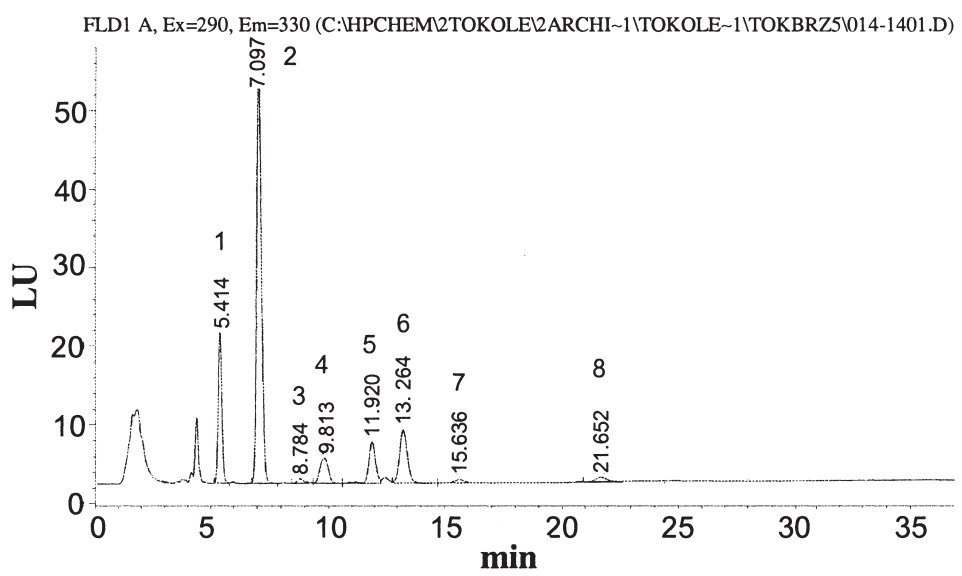

Figure 3. Chromatogram for barley sample analysis: $\alpha$-tocopherol (1), $\alpha$-tocotrienol (2), $\beta$-tocopherol (3), $\gamma$-tocopherol (4), $\beta$-tocotrienol (5), $\gamma$-tocotrienol (6), $\delta$-tocopherol (7), $\delta$-tocotrienol (8)

\section{DISCUSSION}

Adjustment of calibration points to calibration curves, limit of quantitation and ranges of determination. The linear characteristics in the 2-80 ng/injection range for the relationship between detector response and the concentration of the tocols determined $\left(r^{2}>0.999\right)$ were reported by Ryynänen et al. (2004). It should be expected, however, that this characteristics may change into a non-linear form for a wider range of concentrations of the tocols determined. To adjust calibration curves to a wider range of concentrations of the tocols determined, two calibration curves (linear and polynomial) were characterized in the present study. Both concerned a wider range of concentrations than that used in the above study: from approx. 2.5 to approx. $1200 \mathrm{ng} / \mathrm{injection}$. The polynomial $\left(\mathrm{y}=\mathrm{ax}^{2}+\mathrm{bx}+\mathrm{c}\right)$ and linear $(\mathrm{y}=\mathrm{ax}+\mathrm{b})$ calibration curves were characterized by high coefficients of correlation $\left(r^{2}>0.999\right)$, but the fit of calibration points to calibration curves was slightly better for the polynomial calibration, as confirmed by slightly lower residual coefficients of variation for this form of calibration. For this reason, the concentration of tocols in routine analyses was calculated based on polynomial calibration. Using the method described in the present study, it is possible to determine tocols for concentrations as low as $0.05 \mu \mathrm{g} / \mathrm{ml}$. It should be noted, however, that the determination of tocols occurring at such low concentrations is associated with a large error (large uncertainty), resulting mainly from the close proximity of the level of these concentrations to the concentrations of tocols determined in a blank sample and from the poorer fit 
of calibration points to the calibration curve. For this reason, it was appropriate to set two ranges of determination for each tocol, characterized by different uncertainty values.

Repeatability, reproducibility, limit of repeatability. The error expressed in units (standard deviation SD) or the error expressed as relative \% (coefficient of variation $\mathrm{CV}$, or pooled coefficient of variation $\mathrm{CV}_{\mathrm{k}}$ ) can be used to characterize method repeatability and reproducibility. It was assumed that the repeatability was not less than the pooled coefficient of variation for determinations performed with the same method, using identical material, in the same laboratory, by the same laboratory assistant and during the same time period. Reproducibility was defined as being not less than the pooled coefficient of variation for determinations performed using the same method and identical material, in the same laboratory, by different laboratory assistants at different times. The coefficient of variation is the basic parameter for expressing determination error. The values of the coefficients of variation depend on the errors the coefficients contain. These can include errors of determination by the apparatus itself, but can also include other errors, e.g., errors at any stage of sample preparation and errors of determination at different laboratories that use different methods, different laboratory assistants or different determination times (Ellison et al., 2000; Dobecki, 2004). For this reason, the coefficients of variation determined for reproducibility conditions (more error factors) are generally greater than the coefficients determined for certain repeatability conditions (fewer error factors). Ryynänen et al. (2004) reported the results of repeatability and reproducibility studies (as CV) for tocol determinations in rye flour (1.5-19.0\%) and tocopherol determinations in rape seed oil (6.0-36.4\%), showing higher CV values for the determinations of tocols occurring at lower concentrations in the samples and for the determinations of the majority of tocotrienols. The same authors indicated that $\mathrm{CV}$ values also depend largely on the type and uniformity of the material analysed. In the present study, the two parameters that determine variation between analyses (repeatability and reproducibility) were separated, and their values were similar to those reported by Ryynännen et al. (2004).

To determine the criterion of when a given sample should be reanalysed, the limit of repeatability (Dobecki, 2004), assumed to be double the repeatability value, was designated. More specifically, this means that the coefficient of variation for the measurement of two samples of the material analysed using the same method, in the same laboratory, by the same laboratory assistant and during the same time period should not exceed double the repeatability value in more than $5 \%$ of the cases. If this condition cannot be fulfilled, the analysis should be repeated. If the limit of repeatability is exceeded again, it is necessary to extend the limit of repeatability (uncertainty is greater than assumed) for a given sample or series of samples. 
Identification of uncertainty factors and uncertainty of the method. In accordance with the model equation (5), method uncertainty is affected by factors associated with the determination of $\mathrm{C}_{\mathrm{p}}$ and $\mathrm{C}_{\mathrm{bl}}$ concentrations of the tocol analysed, $\mathrm{V}$ volume added to a sample of $1 \%$ isopropanol solution in $n$-hexane ( $/ \mathrm{v})$ after previous evaporation of the extract, dilution $\mathrm{f}_{\mathrm{d}}$, weighed amount of sample $n_{g}$ and recovery R. These factors of uncertainty, resulting from the model equation, can be grouped with regard to a separate factor associated with repeatability and reproducibility - the parameters determined during the validation of the method. This procedure makes it possible to simplify the estimation of method uncertainty, because repeatability and reproducibility tests include most of the uncertainty elements identified with individual parameters of the model equation (Figure 1). These elements, chosen from the sources of uncertainty shown in the diagram and capable of being treated as separate factors of uncertainty that affect method uncertainty, are summarized in the uncertainty budget. These are (figures in brackets designate the numbers of particular parts of the diagram for the sources of uncertainty): repeatability-reproducibility (1), uncertainties of the determinations of blank sample $\mathrm{C}_{\mathrm{bl}}(2)$, apparatus calibration - polynomial curve (2), standard purity (2), recovery R (6), bias of standard solution standardization (2), bias of the pipettes and flasks used for making standard solutions (2), bias of sample preparation (3) and bias of the pipettes and flasks used for dilutions (4). The uncertainty budget does not include factors related to weighing. One of them is the resultant bias, associated with scales error (indicated by a cross-out in part 5 of the diagram, Figure 1). It is reduced to zero because when the weight of a substance is determined, two weighings are actually performed, and the weight of the substance weighed is the difference between gross weight (substance and vessel) and tare weight (vessel alone). The other elements of uncertainty associated with weighing (temperature, humidity, precision of calibration) were not distinguished as separate factors of uncertainty because they were already accounted for in repeatability-reproducibility. The uncertainty budget also includes no temperature factor or factors associated with the precision of pipettes and measuring flasks and the precision of standardization of standard solutions, which, like the analogous factors of weighing uncertainty were already included in repeatability-reproducibility. This procedure is consistent with Ellison et al. (2000), who recommended avoiding double calculation of uncertainty components.

Relative partial standard uncertainties $\mathrm{u}_{\mathrm{i}} \%$ concerning standard purity, standardization of standard solutions (only in the part concerned with bias, not included in repeatability-reproducibility) and the flasks and pipettes used (only in the part concerned with bias) were calculated based on certain threshold errors $a_{i}$ (expressed in relative form, \%). In fact, bias and the $a_{i}$ value that defines it, reflect correctness (or, more appropriately, incorrectness) defined as the difference between 
the mean value estimated based on measurements and the actual value represented by the standard or by the predicted volume (nominal value) of the flask or pipette. Assuming a symmetrical rectangular distribution of the mean values measured around the actual (nominal) value in the range determined by $\mathrm{a}_{\mathrm{i}}$, uncertainties $\mathrm{u}_{\mathrm{i}} \%$ are expressed using the formula $u_{i} \%=a_{i} / \sqrt{ } 3$ (ISO, 1993; Ellison et al., 2000). For flasks and pipettes, $a_{i}$ values were estimated based on the calibration procedure adopted in the laboratory and the resulting guidelines. $a_{i}$ values concerning standard purity and the standardization of standard solutions were estimated based on the manufacturers' declarations (standard purity) or the data from calibrations performed by the service (spectrophotometer-standardization).

For the subsequent estimation of method uncertainty for two concentration ranges, partial standard uncertainties of calibration $\mathrm{u}\left(\mathrm{c}_{0}\right)$ for two threshold values $\mathrm{c}_{0}(0.05$ and $0.80 \mu \mathrm{g} / \mathrm{ml})$ were calculated using the formulas $(6,7,8)$, and converted into relative form $\%$.

Relative partial standard uncertainty of the recovery of a given tocol was calculated statistically as the coefficient of variation for mean arithmetic recovery from 8 measurements.

Combined standard uncertainty was calculated in accordance with the law of uncertainty propagation. First, in accordance with equation (3), calculations were made for partial standard uncertainty for individual determinations related to repeatability-reproducibility $\mathrm{CV}_{\mathrm{k}}$ and for partial standard uncertainty of the blank sample (both expressed in $\mu \mathrm{g} / \mathrm{ml}$ ). The latter was calculated as the standard deviation of the arithmetic mean $(\mathrm{SD} / \sqrt{ } \mathrm{n}, \mathrm{n}=9)$. Combined uncertainty $(\mu \mathrm{g} / \mathrm{ml})$, calculated in this way, was converted into relative value (\%) in relation to two threshold levels of the concentrations of the tocols determined, and composed in accordance with equation (4) with relative standard uncertainty (\%) of the apparatus calibration in relation to standard solutions (polynomial calibration curve, $\mathrm{p}=1$, $\mathrm{n}_{\mathrm{k}}=4$, formula 6), calculated for the same two threshold levels of concentration. These two relative standard uncertainties (calculated for the concentration levels of 0.05 and $0.80 \mu \mathrm{g} / \mathrm{ml}$ ), composed of the three partial uncertainties mentioned above, relate to a single measurement of the sample solution $\left(\mathrm{u}_{1 \text { rep0cal }} \%\right)$. For the material that was analysed twice (two solutions analysed on the chromatograph came from two simultaneously weighted samples of the same material), relative standard uncertainties $\mathrm{u}_{2 \text { rep0cal }} \%$ were calculated (Tables 1 and 2, factor of uncertainty - repeatability-reproducibility, blank sample, apparatus calibration) by dividing $\mathrm{u}_{\text {1rep0cal }} \%$ by $\sqrt{ } \mathrm{n}(\mathrm{n}=2)$. Using relationship (4), uncertainties $\mathrm{u}_{2 \text { rep } 0 \text { cal }} \%$ were composed with the other relative partial standard uncertainties, associated with standard purity, standardization of standard solutions, recovery and with pipettes and measuring flasks used for the analyses. In this way, standard method uncertainties $\left(\mathrm{u}_{668}, \mathrm{P} \leq 0.32\right)$, expressed in $\%$ and related to two levels of 
concentration ( 0.05 and $0.80 \mu \mathrm{g} / \mathrm{ml})$ for each tocol determined, were obtained. To calculate relative uncertainties of the method $\left(\mathrm{U} \%_{95}, \mathrm{P} \leq 0.05\right)$, the relative standard uncertainties obtained above, covering all of the sources of uncertainty identified, were multiplied by the coverage factor $\mathrm{k}_{\mathrm{e}}=2$ (Ellison et al., 2000). Calculation for each substance determined of two relative uncertainties of the method, related to two threshold concentrations, made it possible to estimate method uncertainty in two ranges of concentrations of the tocols determined (Table 3): $0.05-0.80 \mu \mathrm{g} / \mathrm{ml}$ (uncertainty assumed for $0.05 \mu \mathrm{g} / \mathrm{ml}$ ) and above $0.80 \mu \mathrm{g} / \mathrm{ml}$ (uncertainty assumed for $0.80 \mu \mathrm{g} / \mathrm{ml})$.

The fact that method uncertainties were different for both ranges of method uncertainty was due to different relative uncertainties of the factor of repeatabilityreproducibility, blank sample and apparatus calibration $\left(\mathrm{u}_{2 \text { repocal }} \%\right)$, whose effect on combined method uncertainty is the greatest (Figure 2). This factor assumes an exceptionally high value for the determination of tocols occurring at low concentrations $(0.05 \mu \mathrm{g} / \mathrm{ml})$, and then rapidly decreases and stabilizes, starting from the concentration of $\approx 0.80 \mu \mathrm{g} / \mathrm{ml}$ (Table 4). This is due to uncertainty elements associated with blank sample and apparatus calibration, the proportion of which in partial uncertainty $\mathrm{u}_{2 \text { rep } 0 \text { cal }} \%$, and thus in method uncertainty $\mathrm{U} \%{ }_{95}$, decreases with the increasing concentration of the tocols determined, reaching a negligible value close to zero at a concentration of approx. $0.80 \mu \mathrm{g} / \mathrm{ml}$. This is evident in highly similar uncertainty values of repeatability-reproducibility $\mathrm{CV}_{\mathrm{k} 2}\left(\mathrm{CV}_{\mathrm{k} 2}=\mathrm{CV}_{\mathrm{k}} / \sqrt{\mathrm{n}}_{\mathrm{n}}\right.$, $\mathrm{n}=2$ ) and uncertainty $\mathrm{u}_{2 \text { rep } 0 \mathrm{cal}} \%$, estimated for determinations performed in replicate and at two concentration levels: 0.80 and $10 \mu \mathrm{g} / \mathrm{ml}$ (Table 4).

Uncertainty of the determination of eight tocol isomers, estimated at $\mathrm{P} \leq 0.05$, includes all the stages of sample preparation and chromatographic analysis and errors due to other equipment inaccuracy (scales, pipettes and measuring flasks, spectrophotometer), recovery errors, errors related to blank sample determination, calibration of chromatograph and standard purity. Together with the result treated as a mean from the measurements, uncertainty is of practical importance during the interpretation of the result and defines the range (\%) in which the actual result value should be determined with $95 \%$ probability. The uncertainty determined in the present study expresses the error of analyses performed in one laboratory. It should be controlled during every analysis of the samples by checking repeatability, and can be greater for those analyses which fail to meet the repeatability criterion (limit of repeatability).

Recovery. The recovery examined in the current work covered all the analytical procedure and was high in contrast to Czauderna and Kowalczyk (2007) studies, that found serious losses just during saponification. In fact, the tocols recovery values can be included in the broad ranges (58-129\%) and depend on conditions, in wich this process is carried out (Ryynänen et al., 2004). Unlike the studies of 
other authors, the present study determined recoveries for all the eight tocols from cereal samples, which ranged from 93.3 ( $\alpha$-tocotrienol) to $103.1 \%$ ( $\beta$-tocotrienol). The recoveries (\%) obtained in the present study for $\alpha$-tocopherol, $\beta$-tocopherol, $\gamma$-tocopherol and $\delta$-tocopherol $(101.0,101.6,97.1$ and 93.6) are highly similar to those reported by Panfili et al. (2003) and Ryynänen et al. (2004): 96.7, 97.4, 96.2, 104.4 and 94.3, 93.6, 90.3, 91.0, respectively. Similar tocopherol recoveries (91-109\%) to those mentioned above were also reported by Bustamante-Rangel et al. (2007). The recovery of $\alpha$-tocotrienol, obtained in the present study (93.3\%) is similar to that reported by Panfili et al. (98.4\%). The recoveries of $\beta$-tocotrienol, $\gamma$-tocotrienol and $\delta$-tocotrienol, determined in the present study but not in the studies of the above authors were similar to the recoveries of other tocols determined in the present study. The high and similar recoveries that were obtained in most of tests despite methodological differences, are evidence that the tocol determination procedure is effective and repeatable.

Analyses of the materials studied. Barley contains large amounts of $\gamma$-tocotrienol, $\alpha$-tocopherol, $\beta$-tocotrienol and especially $\alpha$-tocotrienol. Among the other tocols, $\delta$-tocopherol is found in very low amounts in barley, usually below LOQ. Mean concentrations of all the tocols in three barley groups $(A, B, C)$ range from 52.7 to $76.1 \mathrm{mg} / \mathrm{kg}$. These observations are consistent with those of Peterson and Quereshi (1993), Peterson (1994), Panfili et al. (2003) and Ryynänen et al. (2004), who reported that the concentration of all tocols in barley range from approx. 37 to $80 \mathrm{mg} / \mathrm{kg}$. The dominant tocol found in wheat and rye is $\beta$-tocotrienol, with lower amounts of $\alpha$-tocopherol, $\alpha$-tocotrienol and $\beta$-tocopherol. Wheat and triticale usually contain zero or little amounts of the other tocols. In the analysed wheat and triticale samples, the mean concentration of all the tocols were 64.7 and $73.4 \mathrm{mg} /$ $\mathrm{kg}$, respectively. These findings are similar to analogous results obtained by other authors. In the studies of Panfili et al. (2003), Bona et al. (2006) and Hidalgo et al. (2006), the concentration of all eight tocol isomers ranged from approx. 32 to 78 $\mathrm{mg} / \mathrm{kg}$ (wheat) and from approx. 45 to $68 \mathrm{mg} / \mathrm{kg}$ (triticale). The present study has confirmed that oat is a main source of $\alpha$-tocotrienol and $\alpha$-tocopherol. It also contains considerable amounts of $\beta$-tocotrienol and $\beta$-tocopherol as well as small amounts of $\gamma$-tocopherol, $\gamma$-tocotrienol and $\delta$-tocotrienol. The mean concentration of all the tocols in the oat sample analysed was $44.5 \mathrm{mg} / \mathrm{kg}$. In the study by Peterson and Quereshi (1993), these concentrations ranged from approx. 19 to $30 \mathrm{mg} / \mathrm{kg}$, and the values reported by Panfili et al. (2003) were approx. $72 \mathrm{mg} / \mathrm{kg}$. Our data are consistent with the results of other authors, although the concentration of individual tocols and their sums may vary according to genotype and region of cultivation (Peterson and Quereshi, 1993; Peterson, 1994; Panfili et al., 2003; Ryynänen et al., 2004). 


\section{CONCLUSIONS}

The results of the validation procedure show that the NP-HPLC method for the determination of eight tocol isomers in cereals, using Lichrospher $\mathrm{Si}$ 60 silica column $(5 \mu)$ and an eluent composed of a mixture of $n$-hexane, ethyl acetate and acetic acid (97.3:1.8:0.9, $\mathrm{v} / \mathrm{v} / \mathrm{v})$ is accurate (CV for repeatabilityreproducibility ranging from 6.2 to $18.4 \%$ ), fast and inexpensive. Method uncertainty was found to be determined by factors related to repeatabilityreproducibility, blank sample and calibration curve. The last two factors strongly increase method uncertainty $(28.9-85.9 \% ; \mathrm{P} \leq 0.05)$ for low tocol amounts $(0.05-0.80 \mathrm{mg} / \mathrm{kg})$. When higher concentrations are determined (above $0.80 \mathrm{mg} / \mathrm{kg})$, the estimated uncertainty of the method $(\mathrm{P} \leq 0.05)$ is much lower $(14.7-27.3 \%)$.

\section{REFERENCES}

AOAC, 1990. Association of Official Analytical Chemists, Official Methods of Analysis. 15th Edition. Washington, DC

Arendarski J. (Editor), 2003. Uncertainty of Measurements (in Polish). Warsaw University of Technology Press, Warszawa, pp. 1-134

Bona L., Kisbocskói N., Hussein D., Farkas R., Szabó E., Hajós G., Acs E., 2006. Antioxidants in triticale grains. In: Proceedings of 6th International Triticale Symposium. Stellenbosch (South Africa) (Abstr.) p. 38

Bustamante-Rangel M., Delgado-Zamarreño M.M., Sánchez-Pérez A., Carabias-Martínez R., 2007. Determination of tocopherols and tocotrienols in cereals by pressurized liquid extraction-liquid chromatography-mass spectrometry. Anal. Chim. Acta 587, 216-221

Czauderna M., Kowalczyk J., 2007. Alkaline saponification results in decomposition of tocopherols in milk and ovine blood plasma. J. Chromatogr. B 858, 8-12

Dobecki M. (Editor), 2004. Assurance of Chemical Analyses Quality (in Polish). Nofer Institute of Occupational Medicine Press, Łódź, pp. 35-111

Eitenmiller R.R., Landen W.O. (Editors), 1999. Vitamins Analysis for the Health and Food Sciences. Boca Raton, CRC Press Inc., pp. 109-134

Ellison S.L.R., Rosslein M., Williams A. (Editors), 2000. Quantifying Uncertainty in Analytical Measurement. Eurachem/Citac Guide, pp. 1-120

Gąsior R., Ślusarczyk K., Szczypuła M., 2005. Validation of a method for determining amino acids in acid hydrolysates of feeds. Ann. Anim. Sci. 5, 181-197

Hidalgo A., Brandolini A., Pompei C., Piscozzi R., 2006. Carotenoids and tocols of einkorn wheat. J. Cereal Sci. 44, 182-193

ISO (International Standards Organization), 1993. Guide to the Expression of Uncertainty in Measurement (in Polish). Central Office of Measures. ISBN 83-906546-1-x, pp. 1-147

Kamal-Eldin A., Görgen S., Pettersson J., Lampi A.-M., 2000. Normal-phase high-performance liquid chromatography of tocopherols and tocotrienols; Comparison of different chromatographic columns. J. Chromatogr. A 881, 217-227 
Packer L., 1995. Nutrition and biochemistry of the lipophilic antioxidants; vitamin E and carotenoids. In: A.S.H. Ong, E. Niki, L. Packer (Editors). Nutrition, Lipids, Health, and Disease. American Oil Chemists' Society, Champaign, IL, pp. 8-35

Panfili G., Fratianni A., Irano M., 2003. Normal phase high-performance liquid chromatography method for the determination of tocopherols and tocotrienols in cereals. J. Agr. Food Chem. 51, 3940-3944

Peterson D.M., 1994. Genotype and environment effects on tocols of barley and oats. Cereal Chem. $71,42-44$

Peterson D.M., Quereshi A.A., 1993. Genotype and environment effects on tocols of barley and oats. Cereal Chem. 70, 157-162

PN-EN ISO/IEC 17025:2005. General Requirements for the Competence of Testing and Calibration Laboratories (in Polish). Polish Committee of Standardization, Warszawa, pp. 37-39

Quereshi A.A., Bradlow B.A., Brace L., Manganello J., Peterson D.M., Pearce B.C., Wright I.J.K., Gapor A., Elson C.E., 1995. Response of hypocholesterolemic subjects to administration of tocotrienols. Lipids 30, 1171-1177

Quereshi N., Quereshi A.A., 1993. Tocotrienols, novel hypocholesterolemic agents with antioxidant properties. In: L. Packer, J. Fuchs (Editors). Vitamin E in Health and Disease. Dekker, New York, pp. 247-268

Quereshi A.A., Sami S.A., Salser W.A., Khan F.A., 2002. Dose-dependent suppression of serum cholesterol by tocotrienol-rich fraction $\left(\mathrm{TRF}_{25}\right)$ of rice bran in hypercholesterolemic humans. Atherosclerosis 161, 199-207

Ryynänen M., Lampi A.-M., Salo-Väänänen P., Ollilainen V., Piironen V., 2004. A small-scale sample preparation method with HPLC analysis for determination of tocopherols and tocotrienols in cereals. J. Food Compos. Anal. 17, 749-765

Schwenke D.C., 2002. Does the lack of tocopherols and tocotrienols put women at increased risk of breast cancer? J. Nutr. Biochem. 13, 2-20

Theriault A., Chao J.T., Wang Q., Gapor A., Adeli K., 1999. Tocotrienol: a review of its therapeutic potential. Clin. Biochem. 32, 309-319 